\title{
Exploration and Understanding of the Management of College Associations
}

\author{
Ni Keqin \\ Wuhan University of Technology \\ Wuhan, Hubei \\ 1003559534@qq.com
}

\begin{abstract}
With the further deepening of China's social reform and higher education reform in recent years, the management of college students' associations will also face new challenges. Under this circumstance, it is particularly important to analyze the problems existing in the construction of the associations, explore the path of social construction, strengthen the management of the associations, and construct a scientific and rational management and operation mode of the associations. Through research and investigation, this paper analyzes the various characteristics of college associations and emphasizes the importance of building quality student associations.
\end{abstract}

\section{Keywords-Association; Participation; Management Research}

\section{THE MANAGEMENT LEVEL AND DEVELOPMENT TREND OF DOMESTIC COLLEGE STUDENT ASSOCIATIONS}

With the vigorous development of college student associations, many scholars have conducted feasibility studies on college associations from different angles.

Starting from the characteristics of student associations, the college student associations in China have dual characteristics: on the one hand, the student associations are subject to the independence of the party committee and the youth league committee of the university, and it is impossible to have complete independence or autonomy, not purely civil organizations; The student associations must start from the interests and needs of the students. Otherwise, they will not be supported and recognized by the majority of students, thus losing the foundation of survival. Therefore, college student associations act as the middle layer of the upper and lower links, and their activities are not self-explanatory and flexible, resulting in insufficient attraction [1].

From the analysis of the types of student associations, we can divide the domestic college student associations into six types: (1) theoretical research, which is the association with theoretical study, propaganda, and research as the main content and purpose; (2) professional knowledge, the type is a society with professional learning, communication, and practice as the main activities; (3) Literary activity, a group formed according to the students' literary talents and common interests, focusing on the pursuit of artistic enjoyment and improving artistic literacy. (4) Sports type, a group formed according to students' sports specialties and common interests; (5) Social service, is a group that serves the society and exercises self; (6) Information transmission, groups that transmit information as the main content, such as youth news agencies and journalists [2].

The United States has the largest number of universities in the world with the strongest strength. At the same time, it has a large number of college student associations. The extracurricular activities of college students are rich and varied. They have accumulated a lot of successful experiences and models in the management and construction of student affairs, which has a good reference for the management of college student associations in China.

With the development of social education, the development environment of university associations is good, and it shows a vigorous development trend. At this stage, the construction of the team of universities in China is becoming more and more perfect, the matching of personnel is becoming more and more reasonable, and the establishment of institutions is gradually increasing. In particular, the support of the school league committee for the construction of colleges and universities is strengthened. In the cognitive perspectives of contemporary students, active participation in association activities has become one of the standards of school life, which reflects the recognition of college students for the associations.

However, in the process of development, there are also some problems in the construction of the associations. First of all, some associations lack management of organizational structures in the construction, and the team members are more mobile. Second, some organizations lack rules and regulations, and people are lazy in their work. Third, the backbone of the associations lacks long-term planning, especially the lack of goal orientation for the future development and recent development of the associations. Fourth, the management of student associations is confusing, and the use of funds is lacking in clarity and objectives. In addition, there are some obstacles in the university student associations such as uneven development, unsound management, and low quality [3].

In the current social context, the in-depth study and reform of college student associations is extremely urgent. It not only affects the healthy growth and comprehensive development of college students, but also relates to the implementation of moral education in colleges and universities. A harmonious society has laid a good foundation for talent. 


\section{MAIN RESEARCH CONTENT AND EXPECTED GOALS}

\section{A. Main research content}

This study attempts to achieve the following two objectives through the current status of management and operation of college students' associations, existing problems and corresponding countermeasures.

1) Objectively describe the current situation and existing problems of the management of college student associations

- In the current situation of colleges and universities, the school association is mixed, some departments are in full swing, and some are arrogant. This is very unreasonable for the distribution of college students. Therefore, this society cannot operate efficiently.

- Some departments are not known at all. When recruiting new people, no one can sign up. If the number of departments is not up, then the work distribution will be unreasonable.

- Some department members are not familiar with each other, and the working group is dead and there is no vitality.

- The department did not respond to the news, and often did not contact people.

- The accumulation of association work to a certain period of time has an impact on students' daily life and affects the normal learning life of students.

2) Constructing the management mode of college student associations in the new era

We hope to develop a student association management information system that adapts to the new situation of the college work environment and work mode, and realize the circulation and sharing of information. The system can timely and accurately feedback the comprehensive information of the students to the student work units, and can assist the officers to complete the task efficiently.

\section{B. Expected goals}

- The main goal of this paper is to explore the nature, function and practice of student associations and to explore the mechanism of the operation, evaluation and development of student associations, and promoting the overall development of students' quality through exploring the mechanism of the operation, evaluation and development of student associations by exploring the overall strategy of student association construction to improving the steady construction of the association.

- Promote the growth and development of students' personality. Explore the effective operation of student association activities and the mechanism of long-term operation under the background of curriculum reform, so that students can do things on the basis of likemindedness, and improve the ability of independent activities, self-management and independent innovation in a democratic and equal atmosphere. Promote the comprehensive and individualized development of students' mind and body.

- Accelerate the professional growth and development of teachers and establish a backbone of teachers who lead and guide the construction of students.

\section{Innovation}

- Fully develop and utilize local curriculum resources. Improve the overall level of team work by using distinctive courses to support the concept of moral education and the moral education system that adapts to the scientific system of social development.

- Bringing into play the unique advantages of the school and the characteristics of traditional school running, so that the idle and wasteful phenomenon of long-term and valuable courses will not be re-emerged, and the status quo of low-level inefficiency of community activities will be improved.

- Create a diverse understanding environment and activity space for students to help students understand the diversity of knowledge.

- Open up the vision of the association guidance teacher and correctly guide the young people to learn to know and learn to live. Better motivate students' creative wisdom. 
TABLE I PLAN PROGRESS

\begin{tabular}{|c|c|}
\hline Achievement & Form \\
\hline $\begin{array}{c}\text { Learn association work opinions, regulations } \\
\text { and related theories. }\end{array}$ & Training sessions \\
\hline $\begin{array}{c}\text { "Solid promotion of association building, } \\
\text { focus on building the school brand" }\end{array}$ & On-site observation \\
\hline $\begin{array}{c}\text { "Growth new stage, community exhibition } \\
\text { style" show report }\end{array}$ & On-site reporting \\
\hline $\begin{array}{c}\text { "Strengthen the construction of association" } \\
\text { school-based curriculum appraisal }\end{array}$ & Case set \\
\hline $\begin{array}{c}\text { "Building a boutique society to highlight the } \\
\text { characteristics of the school " paper rating }\end{array}$ & Report \\
\hline $\begin{array}{c}\text { A report on the "Management Practice and } \\
\text { Research of Association Construction" }\end{array}$ & \\
\hline $\begin{array}{c}\text { Thinking and Research on "Management } \\
\text { Practice of Student Association } \\
\text { Construction" }\end{array}$ & \\
\hline
\end{tabular}

\section{SOCIAL BENEFITS AND EXPECTED RESEARCH RESULTS}

\section{A. Social benefits}

The social significance of this project lies in the use of research on various student associations in various universities to summarize the various forms of management mode of college student associations and to discover the advantages and disadvantages of each other, and promote mutual learning among universities, innovate management methods, improve management efficiency [4]. Help college student associations to develop better and faster, realize and correct the inadequacies of past management models, and gradually become an excellent organization that is more popular with students and more careful and serious in dealing with school affairs. In short, the study of the management mode of student associations in colleges and universities is of great significance to the future development of student associations and can provide reference for various other organizations. Whether it is from the current situation of college development or the future prospects of student organizations, this research is imminent and of great value.

\section{B. Expected research results}

TABLE II EXPECTED RESULT

\begin{tabular}{|c|c|}
\hline Achievement & Form \\
\hline Research Report on Management Mode of College Student Association Management & Report \\
\hline $\begin{array}{c}\text { Working opinions, management regulations and association regulations for the construction of } \\
\text { student associations }\end{array}$ & On-site reporting \\
\hline Association style display report & Proceedings \\
\hline Construction school excellent association paper evaluation & Pror \\
\hline
\end{tabular}

\section{RESEARCH BASIS AND CONDITIONS}

\section{A. Research basis}

a) Student Association: The Student Association is a mass organization formed by students from Chinese secondary schools and colleges on a voluntary basis. These associations can break the boundaries of grades, departments, and schools, unite students with similar interests and interests, and play their role in certain aspects. It specializes in activities that are beneficial to students' physical and mental health."

b) Management mode: The management mode of college student associations refers to the formation of highly authoritative and practical application in the process of service, guidance, adjustment and control of the student associations under certain guiding ideology and guiding principles. Paradigm, which generally includes management objectives, organizational forms, management strategies, and so on.

c) Organizational Behavior Theory: The theory of organizational behavior systematically studies the laws of people's psychology and behavior from the aspects of individual, group, organization and leadership. This theory can improve the management level, especially improve the ability of managers at all levels to predict, guide and control the psychology and behavior of their members, and coordinate the interaction between individuals, groups and organizations in a timely manner, fully play and mobilize the enthusiasm, initiative and creativity of the members of the organization to effectively achieve organizational goals. 


\section{B. Research conditions}

a) Literature data method: Collect research materials related to this topic from ancient and modern Chinese and foreign literature materials, consult a large number of papers, books and newspapers, journals and laws and regulations, and identify, screen and carefully organize the documents[5].

b) Questionnaire method: According to the needs of this study, 600 questionnaires were distributed in Huazhong Agricultural University, Wuhan University, Huazhong University of Science and Technology, Zhongshan University, Zhengzhou University through questionnaire survey, and 558 samples were recovered, with a recovery rate of $93.0 \%$. Among them there are 535 valid questionnaires, the effective recovery rate was $89.2 \%$.

\section{RESEARCH RESULTS}

\section{A. Association member profile}

Freshmen are the most motivated to participate, with $47.7 \%$ of the students and $1.6 \%$ of the seniors. The higher the grade is, the lower the participation is. From the perspective of whether or not they have served as student cadres, the proportion of student cadres participating in the association is 68\%, accounting for the majority, while the non-student cadres are only $32 \%$; from its source, $43 \%$ of students from rural areas, $32 \%$ of students from urban areas, and $25 \%$ from cities.

\section{B. Student participation in association status}

About $59.4 \%$ of students participated in only one association, $34.4 \%$ of students participated in 2 associations, and $6.2 \%$ of students participated in three or more associations. From the perspective of association categories, literature and sports associations are still the focus of students' attention, accounting for $36.7 \%$; followed by academic science and technology. Because such associations are close to the needs of students, they are attracting more and more students, accounting for $26.8 \%$. With the further emphasis and recognition of the youth volunteer service activities, the public welfare practice associations are increasing, ranking third; while the theoretical learning associations are relatively few, less than one-third of the literature and sports associations.

\section{Students' motivation}

The survey found that the motivation of college students' participation is more pragmatic, and about $39.1 \%$ of the respondents said that they participate in the society for "growth of knowledge and exercise ability", followed by "out of interest in association activities" and "for the proportion of students who enrich their after-school life and get to know more friends is $18 \%$, and the proportion of students who have no idea what they are doing in the community is only $3.1 \%$.

\section{Students' understanding of the participating associations}

When asked "How much do you know about your work goals, systems and concepts before joining the association?" When $3.4 \%$ of the students were familiar with the association they participated in, $49.5 \%$ of the students knew better, $30.8 \%$.The students only know a little, and $16.5 \%$ of the students barely understand.

\section{E. Frequency and participation of association activities}

The average student association held 4-6 activities per semester, accounting for $48.4 \%$, followed by $1-3$ and 7-10 times, respectively, $21.9 \%$ and $20.3 \%$, and $9.4 \%$ of associations held more than 10 times. . This shows that the number of activities of the association is acceptable, basically maintained at 4-6 times, which does not affect the students' learning, but also plays a role in enriching campus life.

\section{CONCLUSION}

College student associations, as an important main force in the development of university campus cultural activities, are particularly important for the construction of campus culture. The association has a great influence on the development of students' ideology, which contributes to the improvement and development of students' knowledge structure and provides a high-quality environment for students' ability improvement and skill improvement [6]. It is a good position for students to cultivate their heart and build campus culture.

\section{REFERENCES}

[1] Zheng Shuai, Huo Chen Analysis of the construction and management mode of college student organizations Examination Weekly, 2018(In Chinese)

[2] Cai Liwen, Yang Qinggang, Zhang Haibo, Li Xiichao Analysis of the construction and management mode of college student organizations Time Education, 2015(In Chinese)

[3] Luo Qin Research on the Management Model of College Student Associations in the New Era, 2008(In Chinese)

[4] Weekly pre-pointing, Li Ting. The status and role of college students' associations in ideological and political education in colleges and universities[J]. Journal of Guangxi Youth Cadre College, 2005, (3). (In Chinese)

[5] Chen Wei, Shi Xinming. Guide the development of student associations and enrich the channels of self-education [J]. China Higher Education, 2005, (23). (In Chinese)

[6] Du Xiangfei. Actively explore new models for the construction and management of college students' associations [J]. Journal of Liaoning Administration College, 2005, (4). (In Chinese) 